\title{
Breakthrough behaviour of NBC canister against carbon tetrachloride: a simulant for chemical warfare agents
}

\author{
Avanish Kumar Srivastava, D. Shah, T. H. Mahato, Beer Singh, A. Saxena, A. K. Verma, S. Shrivastava, A. \\ Roy, S. S. Yadav and A. R. Shrivastava \\ Defence Research and Development Establishment, Jhansi Road, Gwalior-474002 (MP), India
}

\author{
Article Info \\ Received 6 February 2012 \\ Accepted 11 April 2012 \\ *Corresponding Author \\ E-mail: beerbs5@rediffmail.com
}

\section{Open Access}

DOI: http://dx.doi.org/ 10.5714/CL.2012.13.2.109

This is an Open Access article distributed under the terms of the Creative Commons Attribution Non-Commercial License (http://creativecommons.org/licenses/ by-nc/3.0/) which permits unrestricted non-commercial use, distribution, and reproduction in any medium, provided the original work is properly cited.

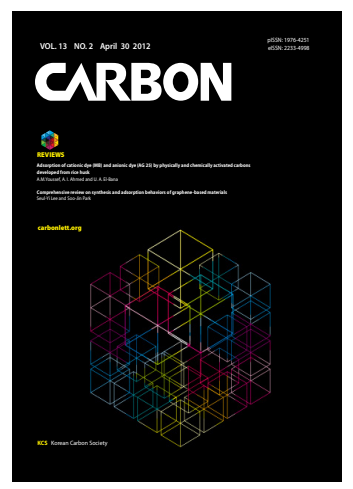

http://carbonlett.org

pISSN: 1976-4251

elSSN: 2233-4998

Copyright $\odot$ Korean Carbon Society

\begin{abstract}
A nuclear, biological, chemical (NBC) canister was indigenously developed using active carbon impregnated with ammoniacal salts of copper (II), chromium (VI) and silver (I), and high efficiency particulate aerosol filter media. The NBC canister was evaluated against carbon tetra chloride $\left(\mathrm{CCl}_{4}\right)$ vapours, which were used as a simulant for persistent chemical warfare agents under dynamic conditions for testing breakthrough times of canisters of gas masks in the National Approval Test of Respirators. The effects of $\mathrm{CCl}_{4}$ concentration, test flow rate, temperature, and relative humidity $(\mathrm{RH})$ on the breakthrough time of the NBC canister against $\mathrm{CCl}_{4}$ vapour were also studied. The impregnated carbon that filled the NBC canister was characterized for surface area and pore volume by $\mathrm{N}_{2}$ adsorption-desorption isotherm at liquid nitrogen temperature. The study clearly indicated that the NBC canister provides adequate protection against $\mathrm{CCl}_{4}$ vapours. The breakthrough time decreased with the increase of the $\mathrm{CCl}_{4}$ concentration and flow rate. The variation in temperature and $\mathrm{RH}$ did not significantly affect the breakthrough behaviour of the NBC canister at high vapour concentration of $\mathrm{CCl}_{4}$, whereas the breakthrough time of the $\mathrm{NBC}$ canister was reduced by an increase of $\mathrm{RH}$ at low $\mathrm{CCl}_{4}$ vapour concentration.
\end{abstract}

Key words: activated carbon, NBC canister, impregnation, carbon tetra chloride vapour, breakthrough time

\section{Introduction}

Atmospheric air is a unique source of oxygen required by humans for respiration. It should be free from toxicants and in breathable form to support life. Contamination of the same can occur either intentionally or accidentally, which can make life difficult. Chemical and biological contaminants with toxic properties have been abused as debilitating agents and have been identified as chemical and biological warfare (CBW) agents [1]. These chemical weapons, when deployed, rapidly fall on to the ground and exist in the environment as aerosols, vapours, and gases, causing incapacitation, and aiding in disarming and capturing the enemy [2].

The only way to overcome the adverse affects of CBW agents is to take proper protective measures. Respiratory protection is of great importance as breathable air is the primary requisite for any individual; such protection can be provided by the gas mask and canister. The performance of the canister mainly depends on the particulate and gas filters. A commonly used particulate filter is the high efficiency particulate aerosol (HEPA) filter media.

Active carbon of high surface area has been widely used for the purification of air and water owing to the adsorption capacity of this universal adsorbent [3-5]. Active carbon removes a wide range of chemicals on the basis of physisorption, which depends on its porous structure. In order to increase the capacity of active carbon for adsorbate degradation it is pre-impregnated with chemicals [6] that add chemical degradation properties to the physi- 
sorption capacity of carbon.

The impregnated carbon is used in nuclear, biological, chemical (NBC) canisters and filters for the removal of persistent and non-persistent chemical warfare $(\mathrm{CW})$ agents. Persistent $\mathrm{CW}$ agents such as blister and nerve agents are mainly held over the adsorbent surface through physical adsorption, while nonpersistant gases such as hydrogen cyanide, cyanogen chloride, and phosgene are converted into non-toxic products by their chemical reaction with impregnated metal salts [4,7-9]. Ideally, the filtration systems should be of such a type that they can provide filtered air against the whole spectrum of chemical warfare agents and not pose any problem of cross contamination; they should also ensure safe handling and disposal. Therefore, there exists a need to develop an NBC canister capable of chemically degrading all types of $\mathrm{CW}$ agents into non-toxic products. It is also necessary to evaluate the developed NBC canister against CW agents.

Indigenously developed NBC canisters have been evaluated against carbon tetra chloride $\left(\mathrm{CCl}_{4}\right)$ or chloropicrin vapours [3] in order to asses these canisters for their protection capacity against $\mathrm{CW}$ agents such as blister agents and nerve agents of high boiling point. $\mathrm{CCl}_{4}$ vapour has long been used as a simulant for $\mathrm{CW}$ agents for testing breakthrough times of gas mask cartridges and canisters in the National Approval Test of Respirators $[2,10,11] . \mathrm{CCl}_{4}$ vapour breakthrough behaviour of an NBC canister is also of great interest when considering respiratory protection.

The requirement of the National Approval Test System was to maintain the continuity of the quality criteria of gas masks through the use of a representative organic vapour for testing breakthrough times of gas mask cartridges and canisters. Every compound has its distinctive adsorption or reactive behaviour with a given adsorbent; therefore, the most useful tests of removal efficiency involve the representative organic vapour to be trapped. Similarity of vapour pressure, water-insolubility, and technical feasibility in generating a test airflow containing the vapour ranging from low to high concentration, and a low risk of toxicity are the primary requirements in attempting to single out a $\mathrm{CW}$ replacement vapour.

$\mathrm{CCl}_{4}$ vapour has also been used for laboratory measurements of adsorbent efficiencies and retentions [2]. Testing of NBC canisters (to be used against CW agents) with a simulant such as $\mathrm{CCl}_{4}$ vapours has several advantages; for example, the test agent has a low toxicity, requires fewer handling precautions, needs fewer special facilities, and has no need for licensing for field use. Such a vapour also allows more frequent tests due to the lower cost of the test agent. There is no CW contamination of the test bed and no release of CW vapour into the effluent [12]. Besides these advantages, the deterioration of the gas removing capacities of cartridges and canisters due to airborne moisture can also be detected by using $\mathrm{CCl}_{4}$ vapours in the test method.

\section{Experimental}

\subsection{Materials/chemicals}

Active carbon coconut shell origin, 90 CTC of $12 \times 30$ BSS $(1.40-0.50 \mathrm{~mm})$ particle size and surface area about $1259 \mathrm{~m}^{2} / \mathrm{g}$, was procured from M/s Active Carbon India, Pvt. Ltd. (Hyderabad, India) and was impregnated with $\mathrm{CuCO}_{3} \cdot \mathrm{Cu}(\mathrm{OH})_{2}, \mathrm{CrO}_{3}$ and $\mathrm{AgNO}_{3}, \mathrm{NaOH}$, and $\mathrm{C}_{5} \mathrm{H}_{5} \mathrm{~N}$. $\mathrm{CCl}_{4}$ (AR grade) was obtained from M/s SD Fine Chemicals. A Mini RAE 3000 VOC monitor from M/s RAE Systems (USA) was used for the detection of $\mathrm{CCl}_{4}$ vapour and a KDS dual- syringe pump series 200 was purchased from Sigma-Aldrich (India).

\subsection{Characterization of impregnated carbon}

Impregnated carbon contained in the NBC canister was characterized prior to its being injected into the NBC canister. Surface area, micro pore volume, cumulative pore volume, and pore size distribution were measured by nitrogen adsorption at $77 \mathrm{~K}$ using an Autosorb 1C from Quantachrome Instruments (USA). The surface area was calculated using the Brunauer-EmmettTeller (BET) method. Micropore volume was calculated with the Dubinin- Radushkevich equation (DR) method and pore maxima for micropores were calculated using the Mikhail, Brunauer, and Bodor (MP) method. The cumulative desorption pore volume was obtained with the Barrett, Joyner, and Halenda (BJH) equation.

Metal ion loading was determined by extracting metal ions from the impregnated carbon in acidic and alkaline media. Copper $(\mathrm{Cu})$, Chromium $(\mathrm{Cr})$, and silver $(\mathrm{Ag})$ ions were extracted as $\mathrm{CuCl}_{2}, \mathrm{Na}_{2} \mathrm{CrO}_{4}$, and $\mathrm{Ag}_{2} \mathrm{~S}_{2} \mathrm{O}_{3}$ using concentrated $\mathrm{HCl}, \mathrm{NaOH}$, and $\mathrm{Na}_{2} \mathrm{~S}_{2} \mathrm{O}_{3}$, respectively, and thereafter estimation was performed with an AAS, GBC Avanta PM, Australia, as well as by the titrimetric method. The extracted concentrations of metal ions were found to be very close to the calculated loading in the impregnated carbon. For scanning electron microscopic (SEM) characterization, the powder samples were first mounted on brass stubs using double sided adhesive tape and then gold coated for 8 min using an ion sputter JEOL, JFC 1100 coating unit. The surface texture of the catalyst was observed using an FEI ESEM Quanta 400. Thermo gravimetric analysis of the catalyst was performed on a thermogravimetric analyzer, TGA-2920, from TA Instruments (USA). Thermograms for the materials were recorded from 30 to $800^{\circ} \mathrm{C}$ at a heating rate of $10^{\circ} \mathrm{C} \mathrm{min}$ ${ }^{1}$ under a nitrogen atmosphere. Bulk density, moisture content, hardness, and ash content were measured using the ASTM test methods D 2854-96, D 2867-95, D 3802-79, and D 2866-94, respectively.

\subsection{Fabrication of NBC canister}

Figs. 1 and 2 show exterior and the cross section of the NBC canister. The NBC canister body (outer part) was made of aluminium and consisted of two main components, i.e., an adsorbent and a particulate filter media. The adsorbent is impregnated carbon (1) and the particulate filter media is HEPA (2), meant for the removal of $\mathrm{CW}$ agents and particulates respectively. Adsorbent in an amount of $100 \pm 5 \mathrm{gm}$, having a height of $2.4 \pm$ $0.5 \mathrm{~mm}$, was placed in between the two perforated discs (3); adsorbent was contained and packed with the help of another perforated disc (3) and crimping was done. The HEPA filter media, made up of borosilicate glass fibres, was used in pleated form in the canister to increase the surface area of the filter media for the effective removal of the particulates. This pleated HEPA filter 


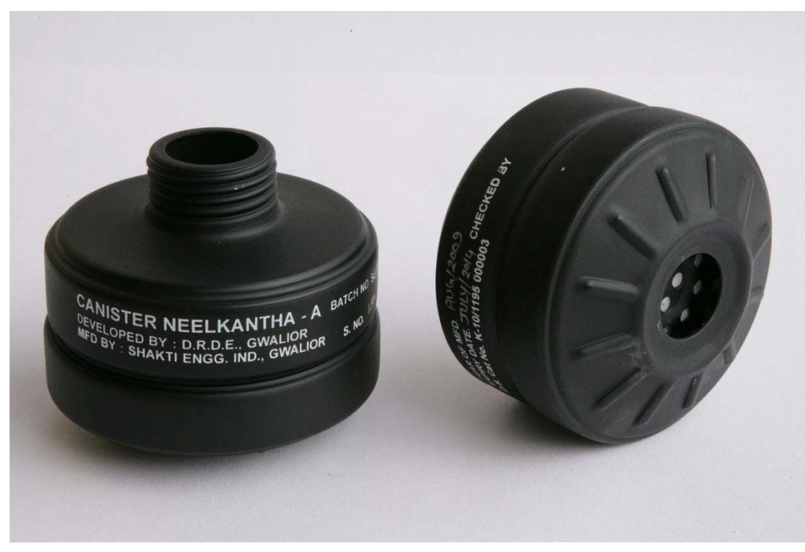

Fig. 1. External view of NBC canister. NBC: nuclear, biological, chemical.

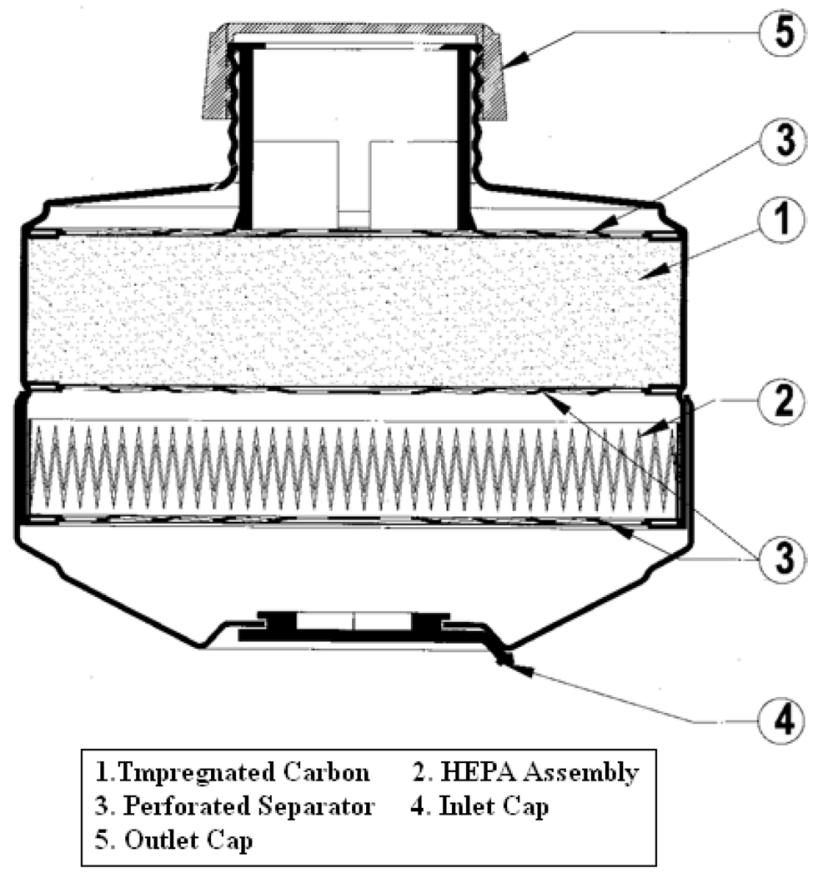

Fig. 2. Cross sectional view of NBC canister. NBC: nuclear, biological, chemical.

media was embedded in the assembly. This HEPA assembly (2), having a width of $13 \mathrm{~mm}$, was supported on a perforated disc (3) made up of aluminium. The diameter of the pores in the perforated disc was $5 \mathrm{~mm}$ and the thickness of the perforated disc was on the order of $1.0 \mathrm{~mm}$. The perforated disc was wrapped with a nonwoven fabric. The canister consists of threads as per EN 148-1-1987EN, which are fitted to the mask. Inlet (4) allows the air to pass through the canister, exiting by way of outlet (5). The diameter of the inlet and outlet of the canister was $28 \mathrm{~mm}$.

\section{4. $\mathrm{CCl}_{4}$ vapour breakthrough measure- ments of NBC canisters}

The schematic test setup for $\mathrm{CCl}_{4}$ vapour breakthrough measurements of NBC canisters is shown in Fig. 3. A blower was
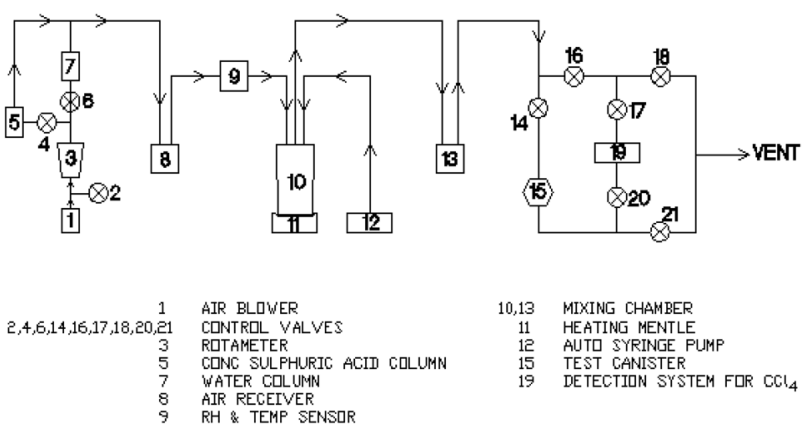

Fig. 3. Test rig for $\mathrm{CCl}_{4}$ vapour adsorption studies of $\mathrm{NBC}$ canister. $\mathrm{NBC}$ : nuclear, biological, chemical.

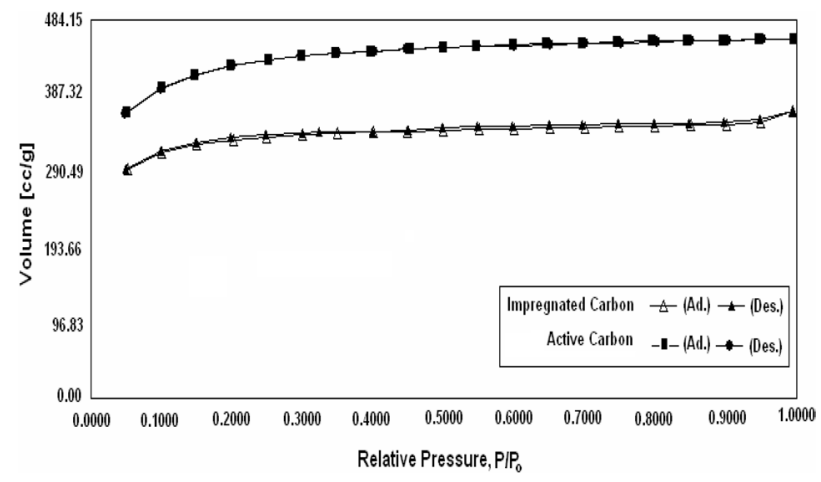

Fig. 4. $N_{2}$ adsorption isotherms of active carbon and impregnated carbon in $\mathrm{N}_{2}$ at $77 \mathrm{~K}$.

used as an air source and air flow was controlled by a rotameter. Relative humidity (RH) was controlled by passing the air through concentrated a sulphuric acid chamber and water chamber. The required concentration of $\mathrm{CCl}_{4}$ vapour was generated by injecting a controlled amount of $\mathrm{CCl}_{4}$ using an auto syringe pump into the mixing chamber, which was maintained at $80^{\circ} \mathrm{C}$. $\mathrm{CCl}_{4}$ vapour breakthrough time and breakthrough concentration $(1 \mathrm{ppm})$ were monitored at the outlet of the test canister with the VOC monitor RAE 3000 equipped with a photo ionization detector of $11.7 \mathrm{eV}$. NBC canisters were evaluated at $30 \mathrm{lpm}$ flow

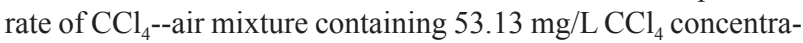
tion, at $30 \pm 2{ }^{\circ} \mathrm{C}$ temperature and $75 \pm 5 \% \mathrm{RH}$. NBC canisters were also evaluated by varying the $\mathrm{CCl}_{4}$ concentration, test flow rate, temperature, and $\mathrm{RH}$ from $5.314-212.52 \mathrm{mg} / \mathrm{L}, 20-35 \mathrm{lpm}$, $20-60^{\circ} \mathrm{C}$ and 20 to $80 \%$, respectively.

\section{Results and Discussion}

\subsection{Textural properties}

Fig. 4 shows the nitrogen adsorption desorption isotherms of active carbon and impregnated carbon; these isotherms indicate that active carbon as well as the impregnated carbon are highly microporous. The only difference between them upon nitrogen adsorption is the value of the saturation plateau obtained at high relative pressures, which indicates different micropore and mesopore volumes [13]. The surface area of active carbon decreased 
Table 1. Surface area and micro pore volume details of the active carbon and impregnated carbon

\begin{tabular}{|c|c|c|c|c|c|}
\hline \multirow{2}{*}{ Carbon systems } & \multirow{2}{*}{$\begin{array}{l}\text { Surface area } \\
\left(\mathrm{N}_{2} \mathrm{BET}\right) \\
\left(\mathrm{m}^{2} / \mathrm{g}\right)\end{array}$} & \multirow{2}{*}{$\begin{array}{l}\text { Micro pore volume } \\
\left(\mathrm{N}_{2} \mathrm{DR}\right)\left(\mathrm{cm}^{3} / \mathrm{g}\right)\end{array}$} & \multirow{2}{*}{$\begin{array}{l}\text { BJH cumulative desorption } \\
\text { pore volume }\left(\mathrm{N}_{2} \mathrm{BJH}\right) \\
\left(\mathrm{cm}^{3} / \mathrm{g}\right)\end{array}$} & \multicolumn{2}{|c|}{ Pore maxima $(\AA)$} \\
\hline & & & & (micropore) & (mesopore) \\
\hline Active carbon & 1259 & 0.70 & 0.33 & 9.26 & 23.29 \\
\hline Impregnated carbon & 1022 & 0.54 & 0.24 & 9.31 & 21.36 \\
\hline
\end{tabular}

BET: Brunauer-Emmett-Teller, DR: Dubinin- Radushkevich, BJH: Barrett, Joyner, and Halenda.
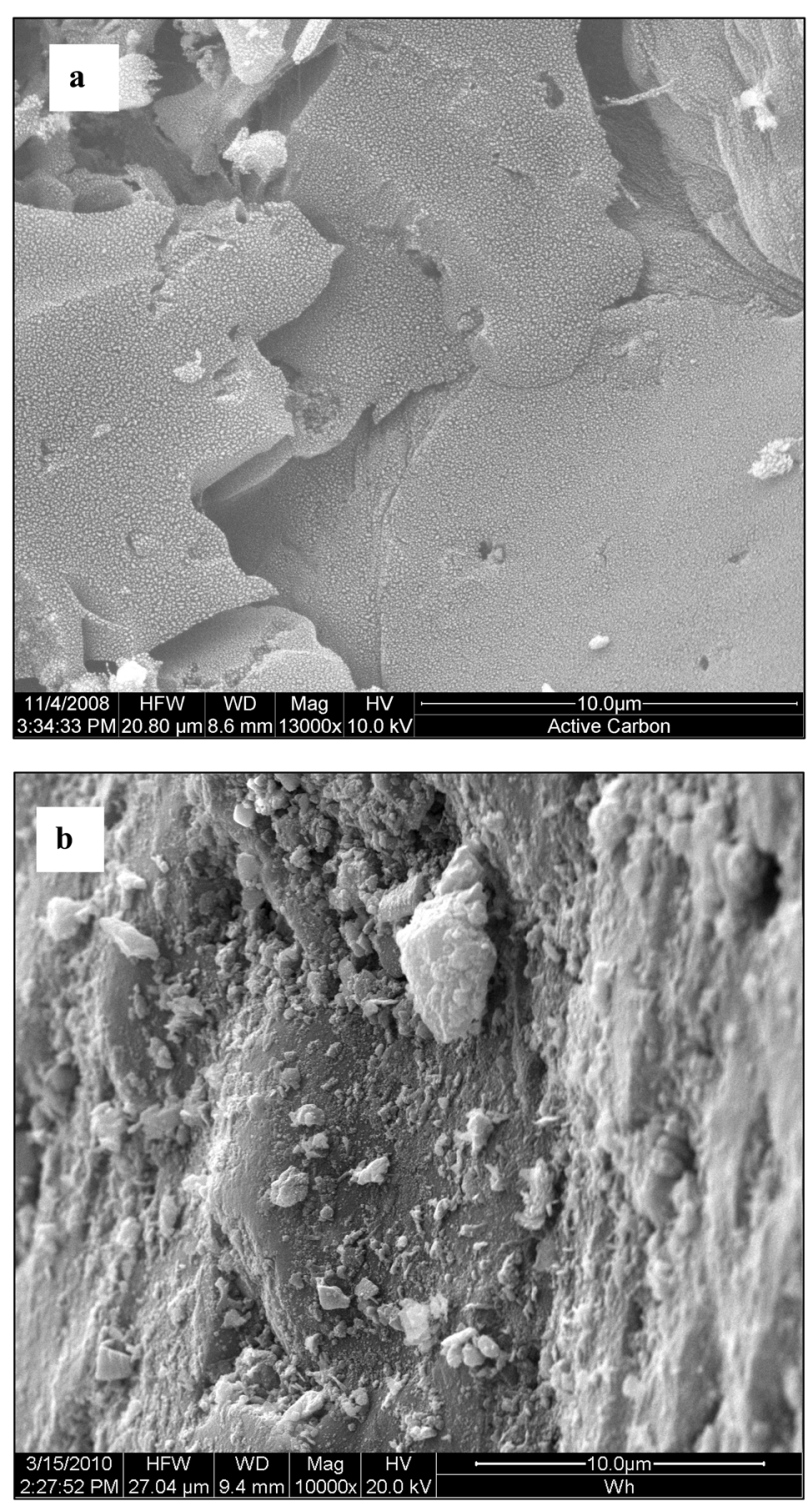

Fig. 5. Scanning electron microscopic images of (a) active carbon (b) impregnated carbon.

after impregnation from 1259 to $1022 \mathrm{~m}^{2} / \mathrm{g}$. This decrease was due to impregnants, which during impregnation travel through the macro pores and get deposited in the mesopores or the pore openings of micropores, hence causing the blockage of the meso and micro pores. The $\mathrm{N}_{2}$ DR micropore volume and $\mathrm{N}_{2}$ BJH cumulative desorption pore volume also indicated the decrease in

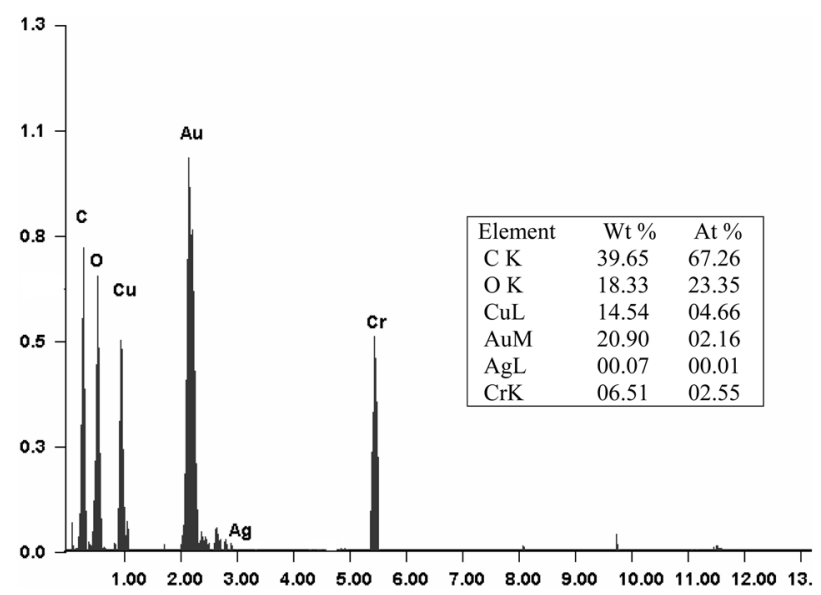

Fig. 6. energy dispersive X-ray spectroscopy spectra of active carbon and impregnated carbon.

micropore and mesopore volume, as shown in Table 1.

The SEM images of active carbon and impregnated carbon are shown in Figs. 5a and b. One SEM image of active carbon shows considerable small cavities, cracks and attached fine particles over the surface, forming a system of complicated pore networks (Fig. 5a). Impregnation of metal salts leads to the clogging of the cracks and cavities by the adsorbed metal salts and dispersal of metal salts on the surface of the impregnated carbon (Fig. 5b). Another SEM image of impregnated carbon clearly shows the metal salt particles as white spots. The energy dispersive X-ray spectroscopy (EDX) spectra of the impregnated carbon are shown in Fig. 6. The EDX spectra of the impregnated carbon confirm the presence of $\mathrm{Cu}, \mathrm{Cr}$, and $\mathrm{Ag}$.

Fig. 7 illustrates the weight change as a function of temperature for active carbon and impregnated carbon in a nitrogen atmosphere. The weight loss as a function of temperature was monitored and used to understand the effect(s) of the metal impregnants on the deterioration of the impregnated carbon. Adsorbed moisture starts getting removed at $110^{\circ} \mathrm{C}$. Fig. 7 shows weight losses of about 1.5 and $3.0 \%$ in active carbon and impregnated carbon, respectively, at a temperature of about $110^{\circ} \mathrm{C}$ because of the loss of adsorbed water molecules (moisture). Impregnated carbon exhibited a steady rate of weight loss up to $280^{\circ} \mathrm{C}$. About $7 \%$ weight loss took place between $280-380^{\circ} \mathrm{C}$. At temperatures higher than $380^{\circ} \mathrm{C}$, a marked increase in weight loss was observed up to $800^{\circ} \mathrm{C}$. Ehrburger et al. [14] have reported similar results for chromium impregnated carbon. This exotherm is believed to be due to the oxidation of the carbon matrix by the impregnant species. This hypothesis is supported by the behaviour of the active carbon in locations where there are 


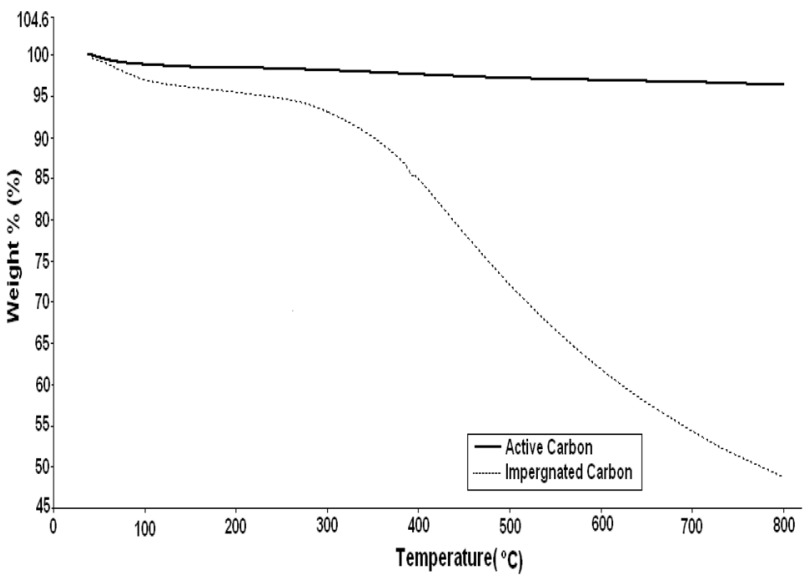

Fig. 7. Thermogravimetric analysis curves of active carbon and impregnated carbon.

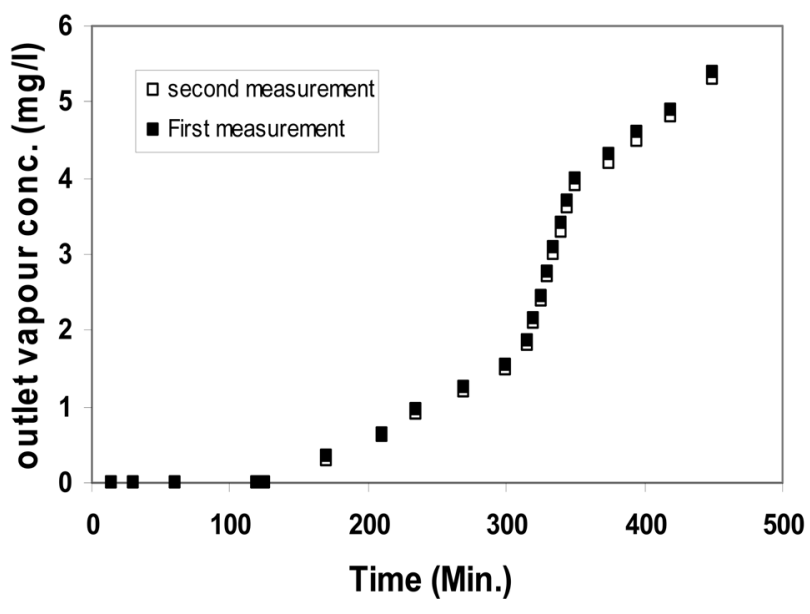

Fig. 8. Vapour concentration of $\mathrm{CCl}_{4}$ at the outlet of $\mathrm{NBC}$ canister at 5.313 $\mathrm{mg} / \mathrm{LCCl}_{4}$ inlet concentration. NBC: nuclear, biological, chemical.

no impregnants available to oxidize the carbon. Active carbon and impregnated carbon have bulk densities of 0.32 and $0.50 \mathrm{~g} /$ $\mathrm{mL}$ respectively. The bulk density of impregnated carbon was found to be higher than that of the active carbon because pores in the impregnated carbon were occupied by impregnants, i.e., the weight increases, whereas the outer surface volume of the material remains the same, and hence the density increases. The moisture content levels of active carbon and impregnated carbon were found to be 5.0 and $1.0 \%$, respectively. The hardness values of both the active carbon and the impregnated carbon were found to be greater than $95 \%$.

\subsection{Breakthrough behaviour of NBC canister against $\mathrm{CCl}_{4}$ vapours}

The stability of the $\mathrm{CCl}_{4}$ vapour concentration in the test airflow was monitored before evaluation of the NBC canisters. The coefficient of variation (CV) of $\mathrm{CCl}_{4}$ vapours at different concentrations was found to be within the same range, from 1 to $1.2 \%$. High reproducibility of the $\mathrm{CCl}_{4}$ vapour concentration in the test airflow was also indicated by the breakthrough curves obtained by duplicated measurements, shown in Fig. 8; these

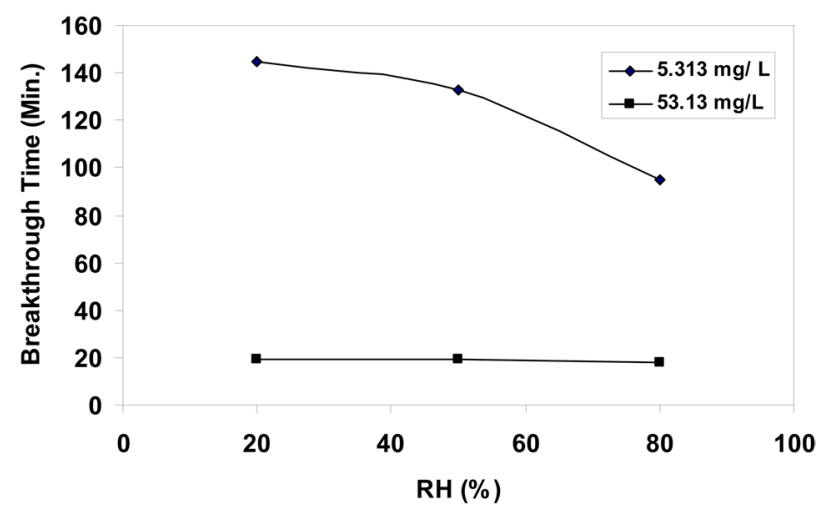

Fig. 9. Effect of relative humidity on the $\mathrm{CCl}_{4}$ vapour breakthrough behaviour of NBC canister at 5.313 and $53.13 \mathrm{mg} / \mathrm{L}$. NBC: nuclear, biological, chemical.

measurements agreed well with each other. This means that the apparatus generated a stable concentration. The breakthrough times of the cartridges or canisters are defined, on principle, as the time when the vapour begins to leak from the test piece at the maximum permissible concentration for the wearers; however, this value is conventionally set at $1 \mathrm{ppm}$ in this study.

\subsection{Effect of $\mathrm{CCl}_{4}$ concentration, test flow rate, and temperature}

It was observed that the breakthrough time of the NBC canister decreases with the increase of the vapour concentration of $\mathrm{CCl}_{4}$ [15]. At inlet concentrations of 13.28, 26.56, 53.13, 106.26, 159.39 , and $212.52 \mathrm{mg} / \mathrm{L}$ the breakthrough times were observed to be $82,39,19,10.5,7$, and $5.5 \mathrm{~min}$, respectively, at $30 \mathrm{lpm}$ flow rate. It was also observed that with the increase of the test flow rate and temperature, the breakthrough time of the NBC canister decreased. At inlet flow rates of 20, 25, 30, and $35 \mathrm{lpm}$ the NBC canister showed breakthrough times of $15,13,10.5$, and $7 \mathrm{~min}$, respectively, at the inlet concentration of $53.13 \mathrm{mg} / \mathrm{L}$. With increasing flow rate, the breakthrough time decreases due to there being less contact time [2]. The contact time decreases from 0.56 to $0.32 \mathrm{~s}$ when the flow rate increases from 20 to 35 lpm. In the temperature range of $20-40^{\circ} \mathrm{C}$, the $\mathrm{NBC}$ canister showed a breakthrough time of $19 \mathrm{~min}$, whereas the increase of temperature from 40 to $60^{\circ} \mathrm{C}$ resulted in a decrease of the breakthrough time to $18 \mathrm{~min}$. This may be attributed to the decrease in adsorption of $\mathrm{CCl}_{4}$ vapours at higher temperature [2].

\subsection{Effect of relative humidity}

The performance of the $\mathrm{NBC}$ canister against a $\mathrm{CCl}_{4}$-air mixture having 53.13 and $5.313 \mathrm{mg} / \mathrm{L}$ concentrations at different $\mathrm{RH}$ under the aforesaid experimental conditions is presented in Fig 9. The figure indicates that the NBC canister does not show much variation in the breakthrough behaviour of $\mathrm{CCl}_{4}$ vapour in the range of 20 to $80 \% \mathrm{RH}$ at $53.13 \mathrm{mg} / \mathrm{L}$, due to the lowered susceptibility of the NBC canister with coexisting moisture. This can be attributed to the fact that higher concentrations of $\mathrm{CCl}_{4}$ vapour cause a stronger exothermic reaction, which results in an increase of the temperature of the adsorbent. This sudden increase of temperature nullifies the effect of high humidity. The 
breakthrough behaviour of the NBC canister at $5.313 \mathrm{mg} / \mathrm{L}$ indicates that at lower $\mathrm{CCl}_{4}$ vapour concentrations $\mathrm{RH}$ affects the breakthrough time. An increase of RH from 20 to $80 \%$ at 5.313 $\mathrm{mg} / \mathrm{L}$ results in a decrease of the breakthrough time from 145 to $95 \mathrm{~min}$. This apparent difference in the breakthrough behaviour of the $\mathrm{NBC}$ canister against $\mathrm{CCl}_{4}$ vapour at high $\mathrm{RH}$ can be interpreted through the idea that $\mathrm{CCl}_{4}$ and $\mathrm{H}_{2} \mathrm{O}$ molecules adsorb competitively on carbon, which in turn results in a blockage of active sites of the carbon by $\mathrm{H}_{2} \mathrm{O}$ adsorption [16].

\section{Conclusions}

The breakthrough behaviour of an indigenously developed $\mathrm{NBC}$ canister for $\mathrm{CCl}_{4}$ vapours was studied and interpreted in terms of the $\mathrm{CCl}_{4} \mathrm{BTT}$ value. The effects of various parameters such as $\mathrm{CCl}_{4}$ vapour concentration, test flow rate, temperature, and $\mathrm{RH}$ were also studied. The results showed that $\mathrm{CCl}_{4} \mathrm{BTT}$ values were observed to decrease with the increase of $\mathrm{CCl}_{4}$ concentration and inlet flow rate. The variation in temperature and $\mathrm{RH}$ did not have much effect on the $\mathrm{CCl}_{4}$ breakthrough behaviour of the $\mathrm{NBC}$ canister at high vapour concentration of $\mathrm{CCl}_{4}$, whereas the breakthrough times of the $\mathrm{NBC}$ canister were shortened by an increase of $\mathrm{RH}$ at low $\mathrm{CCl}_{4}$ vapour concentration. Therefore, it can be concluded that the indigenously developed $\mathrm{NBC}$ canister, having $\mathrm{Cu}, \mathrm{Cr}$, and $\mathrm{Ag}$ impregnated carbon, is a promising device that can be used for protection against deadly toxic $\mathrm{CW}$ agents.

\section{Acknowledgements}

We thank Dr. R. Vijayaraghavan, Director, D.R.D.E., Gwalior, for providing lab facilities to carry out this work and also for his keen interest and encouragement.

\section{References}

[1] Waitt AH. Gas Warfare: the Chemical Weapon, its Use, and Protection Against it. Rev. ed., Duell, Sloan, and Pearce, New York (1944).

[2] Noyes WA. Military Problems with Aerosol and Nonpersistant Gases. Summary Technical Report Division 10, Vol. 1. National Defense Research Committee, Washington, DC (1946).
[3] Singh B, Saxena A, Sharda D, Yadav SS, Pandey CD, Sekhar K. Evaluation of NBC canisters against phosgene-a chemical warfare agent. Def Sci J, 55, 437 (2005).

[4] Jonas LA, Rehrmann JA. Predictive equations in gas adsorption kinetics. Carbon, 11, 59 (1973). http://dx.doi.org/10.1016/00086223(73)90008-0.

[5] Wood GO, Stampfer JF. Adsorption rate coefficients for gases and vapors on activated carbons. Carbon, 31, 195 (1993). http://dx.doi. org/10.1016/0008-6223(93)90172-7.

[6] Singh B, Madhusudhanan S, Dubey V, Nath R, Rao NBSN. Active carbon for removal of toxic chemicals from contaminated water. Carbon, 34, 327 (1996). http://dx.doi.org/10.1016/00086223(95)00179-4.

[7] Wagner GW, Bartram PW. Reactions of the nerve agent simulant diisopropyl fluorophosphate with self-decontaminating adsorbents. A 31P MAS NMR study. J Mol Catal A: Chem, 144, 419 (1999). http://dx.doi.org/10.1016/s1381-1169(98)00343-4.

[8] Singh B, Madhusudanan S, Kumar CGP, Sachan SRS, Pandey SK, Agarwal S. Determination of copper, total chromium and silver in impregnated carbon. Def Sci J, 48, 365 (1998).

[9] Barnir Z, Aharoni C. Adsorption of cyanogen chloride on impregnated active carbon. Carbon, 13, 363 (1975). http://dx.doi. org/10.1016/0008-6223(75)90003-2.

[10] Standards for Gas Mask. Ministry of Labour Notification No. 68 of September 26 (1990).

[11] Standards for Gas Mask. Ministry of Labour Notification No. 1 of January 8 (1996).

[12] Srivastava AK, Saxena A, Singh B, Srivas SK. Development and evaluation of impregnated carbon systems against iodine vapours. Carbon Lett, 8, 274 (2007).

[13] Cordero T, Rodriguez-Mirasol J, Tancredi N, Piriz J, Vivo G, Rodriguez JJ. Influence of surface composition and pore structure on $\mathrm{Cr}(\mathrm{III})$ adsorption onto activated carbons. Ind Eng Chem Res, 41, 6042 (2002). http://dx.doi.org/10.1021/ie020210f.

[14] Ehrburger P, Dentzer J, Lahaye J, Dziedzinl P, Fangeat R. Thermal behavior of chromium trioxide deposited on carbon. Carbon, 28, 113 (1990). http://dx.doi.org/10.1016/0008-6223(90)90101-4.

[15] Nelson GO, Harder CA. Respirator cartridge efficiency studies. 5. Effect of solvent vapor. Am Ind Hyg Assoc J, 35, 391 (1974). http://dx.doi.org/10.1080/0002889748507051.

[16] Moyer ES, Peterson JA. Organic vapor (OV) respirator cartridge and canister testing against methylene chloride. Appl Occup Environ Hyg, 8, 553 (1993). http://dx.doi.org/10.1080/104732 2x.1993.10388159. 